\title{
What if there were no fishing? North Atlantic right whale population trajectories without entanglement mortality
}

\author{
Robert D. Kenney* \\ University of Rhode Island, Graduate School of Oceanography, Bay Campus Box 40, 215 South Ferry Road, Narragansett, \\ Rhode Island 02882-1197, USA
}

\begin{abstract}
The North Atlantic right whale Eubalaena glacialis, one of the world's rarest mammals, experienced an alarming level of mortality in 2017. The estimated abundance as of 2016 was 451 animals. After $20 \mathrm{yr}$ of relatively steady but slow growth, the population has declined since 2010. Mortality and serious injury from entanglement in commercial fishing gear have had a significant impact on recovery. Despite legal requirements to reduce fishery-related mortality, little or no real progress has been made over the last 2 decades. Here I took a relatively simple approach to estimate what the population trajectory since 1990 might have been under 4 different scenarios of reduced entanglement mortality. Under the best-case scenarios, the population at the end of the time-series would have been $25-30 \%$ higher than observed at present. If the population had not experienced nearly 3 decades of increasing entanglement, it could have been much more resilient to a disaster year like 2017.
\end{abstract}

KEY WORDS: Eubalaena glacialis - North Atlantic right whale - Population decline · Entanglement mortality

\section{INTRODUCTION}

The North Atlantic right whale Eubalaena glacialis (NARW) population experienced a disastrous year in 2017 (Pennisi 2017). Seventeen whales are known to have died, including 12 in the Gulf of St. Lawrence, Canada, and the US National Marine Fisheries Service (NMFS) has formally declared that an Unusual Mortality Event (UME) is underway (https://www. fisheries.noaa.gov/national/marine-life-distress/20172018-north-atlantic-right-whale-unusual-mortalityevent). The NARW has been recognized as one of the world's rarest mammals (Kraus et al. 2005, Cooke 2018), with anthropogenic mortality from vessel colli-

*Corresponding author: rkenney@uri.edu sions and entanglement in commercial fishing gear causing significant impacts on population growth and recovery. Even before the 2017 spike in mortalities, however, the population was beginning to decline.

Pace et al. (2017) developed a Bayesian markrecapture model, based on repeated sightings of known individuals, to estimate abundance and to monitor changes in the NARW population, which also produced annual estimates of age- and sex-specific mortality. Their results showed a population that grew from 270 whales in 1990, peaked in 2010, and thereafter slowly declined to 458 in 2015 . Pettis et al. (2017) extended the model for an additional year, with the decline continuing to 451 in 2016 . The decline

() The author 2018. Open Access under Creative Commons by Attribution Licence. Use, distribution and reproduction are unrestricted. Authors and original publication must be credited. 
after 2010 did not correspond to any detectable change in mortality rate (Pace et al. 2017), but did coincide with a substantial decrease in calving over that period (Pettis et al. 2017). The result is that births are no longer sufficient to replace animals lost to mortality from all sources. The cause of the decline in reproduction is not known, but most likely is due to climatechange-related alterations in food resources (MeyerGutbrod et al. 2015), and possibly also to changes in health status (Rolland et al. 2016), noise stress (Hatch et al. 2012), and sub-lethal effects of entanglement (van der Hoop et al. 2016, 2017).

In 1994, the US Congress re-authorized and amended the Marine Mammal Protection Act (MMPA). One of the substantial changes was the creation of a new regime for assessing and mitigating the effects of fishery by-catch on marine mammals. This involves the publication and regular updating of a Stock Assessment Report (SAR) for each individual marine mammal stock within US jurisdiction, with the advice of an external Scientific Review Group (SRG). The most recently published SAR for the Atlantic and Gulf of Mexico is the 2017 edition (Hayes et al. 2018); all versions, as well as the most recent draft when released for public review and comment, are available online (NMFS 2018). The MMPA requires each SAR to assess stock abundance, trend, and mortality. The assessment involves computing an abundance-based threshold for allowable mortality, known as Potential Biological Removal (PBR). For stocks where fishery-related mortality and serious injury (M\&SI) exceed PBR, a Take Reduction Team may be empaneled. The Team is tasked under the MMPA with developing a plan to reduce M\&SI below PBR within 6 mo and to near 0 within 5 yr. The Atlantic Large Whale Take Reduction Team (ALWTRT) was established in 1996 and has now been working for 2 decades to reduce fishery-related mortalities of NARWs, as well as of humpback whales Megaptera novaeangliae, fin whales Balaenoptera physalus, and minke whales B. acutorostrata. I have served on both the Atlantic SRG and the ALWTRT since about 1996, so have been closely involved in both the stock-assessment and take-reduction processes.

The ALWTRT met in Providence, Rhode Island, USA, in April 2017 (prior to the UME) to review recent findings and discuss potential new strategies for reducing fishery-related mortality. Several presentations of recent research, including the study by Pace et al. (2017), made it clear that the NARW population is in decline and that both the rate and severity of entanglements are increasing. The fishing industry rep- resentatives on the ALWTRT suggested that it was unfair either to blame fishing for the status of the population or to add additional or more stringent regulations if climate change was the main culprit for the decline. Comments were made suggesting that the population would have been declining even without fishery-related mortality, so that further reductions in M\&SI would be futile. I undertook the present study to explore 4 different 'what if' scenarios asking what the past population trajectories might have looked like with reduced or even no fishery-related mortality:

(1) What if the detected fishery-related mortality of right whales had been reduced to nil?

(2) What if the Take Reduction Plan had been successful and reduced detected fishery-related mortality to no greater than PBR in any year?

(3) Recognizing that we do not detect every dead right whale, what if fishery-related mortality had been entirely eliminated?

(4) What if all of the females known to have been killed or injured had been allowed to survive and to continue calving?

An additional objective was to conduct the study in such a way that non-statisticians would be able to understand what was done (or to repeat it themselves) more easily than they understand sophisticated modeling approaches.

\section{METHODS AND RESULTS}

The baseline for my analysis was the time-series of abundance estimates from 1990 to 2016 from Pace et al. (2017) and Pettis et al. (2017), as well as the PBR and mortality numbers from the complete series of SARs. Table S1 (in the Supplement at www.int-res. com/articles/suppl/n037p233_supp.pdf) includes all of the input values used in the study and supporting explanatory details, as well as the resulting timeseries. Each SAR includes estimates of minimum population size and the resulting PBR, as well as a table of year-by-year tallies of detected humanrelated M\&SI (i.e. 'body counts') — classified by vessel strike, fishery entanglement, or other. I included only fishery-related M\&SI for this analysis. Tracking the M\&SI data through the SARs is complicated, since assessments of a given incident can change over time, some records may be added several years after the fact, and others can be included for 1 or $2 \mathrm{yr}$ and then deleted as better information becomes available. Table S2 in the Supplement is a complete record of every fishery-related incident from all of the SAR tables from 1995 through 2018, identifying 
any that were subsequently deleted and not included in the analysis here.

The baseline abundances from Pace et al. (2017) and Pettis et al. (2017) begin at 270 in 1990, increase to a peak at 482 in 2010, and then decline to 458 in $2015(95 \%$ credible interval $=444-471)$ and 451 in 2016 (red line in Fig. 1). Up to about 2010, they closely match the minimum abundances previously reported in the SARs, which had been calculated as the minimum number alive each year, i.e. the sum of all animals seen within that year plus any seen both before and after.

Scenario 1 assumed that the detected fisheryrelated M\&SI was 0 in every year. This was done by adding the reported dead and seriously injured whales from the SARs back to the baseline population. The resulting population trajectory began at the same 270 in 1990, increased to a maximum of 515 in 2012, and then declined to 506 in 2015 and 2016 (dark blue line in Fig. 1).

Scenario 2 was to slightly relax the assumption of eliminating all detected M\&SI and to allow fisheryrelated mortality to be no higher than PBR in any year. The method for calculating PBR was designed such that if anthropogenic mortality were reduced to

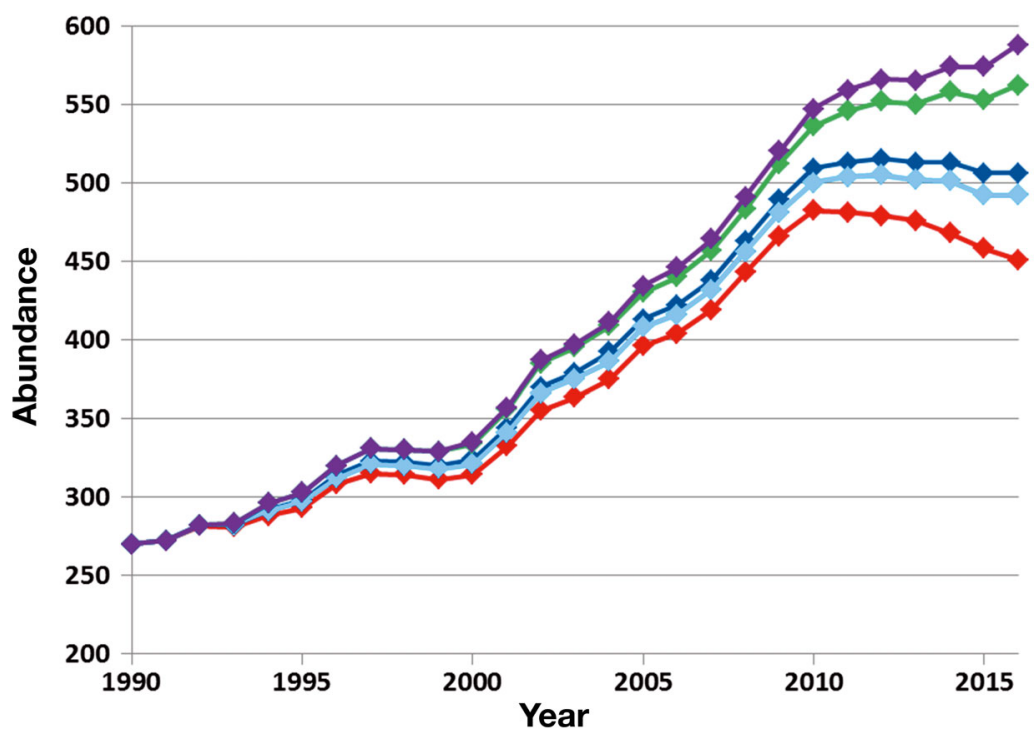

Fig. 1. Trajectories of North Atlantic right whale abundance from 1990 to 2016 under differing levels of mortality and serious injury from fishing gear entanglement. The red line is the observed baseline condition from Pace et al. (2017) and Pettis et al. (2017). The dark blue line is the trend if the detected entanglement mortalities reported in the annual Stock Assessment Reports were all eliminated (Scenario 1). The light blue line is the trend if detected mortality was less than or equal to Potential Biological Removal in every year (Scenario 2). The green line assumes that actual entanglement mortality is twice that detected and reported and sets that to 0 (Scenario 3). The purple line assumes that all known females that were removed continued to calve at 5 yr intervals after a first calf at age 10 (Scenario 4) below PBR, an endangered population would have a much higher likelihood of recovery (Wade 1998). The (1) between detected M\&SI and PBR for each (or the detected M\&SI if it was already lower ore decreasing to 492 in 2015 and 2016 (light blue Fig. 1).

M\&SI numbers included in the SARs are recand recovered (or at least well-photographed) carcestimates of true morrates. The actual levels of mortality are cerhigher. Based on the sighting histories, Pace et related M\&SI from the data in Table S1 was $0.5 \%$, and the highest values were $1.7 \%$ in both 2014 and 2016. Kraus et al. (2005) estimated that the detection rate of dead whales was only $17 \%$, suggesting that actual mortality could be nearly 6 times the detected number. Pace et al. (2017) estimated total entanglement mortality to be at least double the minimum number detected and reported in the SARs, and concluded that their estimate was still likely to be biased low. Scenario 3 in this analysis took the more conservative of those 2 proportions, i.e. $50 \%$ (Pace et al. 2017), to estimate the total numbers of whales killed or injured by entanglement. Therefore, twice the detected M\&SI was added back to the baseline. From the same beginning abundance of 270 whales in 1990, the hypothetical population increased to 552 in 2012 and then fluctuated up and down for the last $4 \mathrm{yr}$ of the time-series (550-558-553-562) (green line in Fig. 1). With assumed 0 entanglement mortality, population growth would have slowed, but would not have reversed to a clear decline.

Scenario 4 recognized that removing a female from the population also removes her future reproductive contributions. Of the 58 whales recorded in the SARs as killed or seriously injured by entanglement between 1993 and 2016 (Table S2), 32 were male, 15 were female, and 11 were unknown gender. Reproductive 
histories and ages were obtained from the North Atlantic Right Whale Consortium catalog (Hamilton et al. 2009). Each adult female was assumed to continue calving at $5 \mathrm{yr}$ intervals from her last known calfselected as a conservative value from a population history where it has varied from 3 to 10 yr (Kraus et al. 2009, Pettis et al. 2017). Younger females were assumed to give birth to a first calf at age 10 and then continue at the same $5 \mathrm{yr}$ intervals. No assumptions were made about unknown gender animals, which would also include any projected calves. This process resulted in 26 additional calves added back to the population (Table S2). The resulting trajectory began from 270 in 1990 and reached a maximum of 588 in 2016, with no decline at the end of the time-series (purple line in Fig. 1).

\section{DISCUSSION}

The 4 hypothetical right whale population trajectories that are presented here are derived from the observed abundances by changing only M\&SI from fishery entanglement. Every other source of possible impact on the population that is known or suspected to have occurred is still included in all 5 time-series, including vessel strikes, calving declines, climate change, resource limitation, sub-lethal entanglement effects, disease, predation, and ocean noise, among other potential factors. It is important to note that neither this study, nor the study by Pace et al. (2017) that provided the baseline abundance data, is a true population-dynamics model that might be projected into the future. Pace et al. (2017) used individual sighting histories to generate maximum-likelihood estimates of annual abundance. In fact, one of their principal objectives was to find a better way of estimating abundance for the SAR, since the minimum number alive method was becoming less reliable as re-sighting probabilities were getting lower and more variable (e.g. see Fig. 2a in Pace et al. 2017). Changes in abundance were used to estimate population growth, and disappearances of individuals were used to estimate survival and mortality. However, the sort of parameters that would be included in a population model, such as fecundity and density-dependence, were not explicitly included other than being recognized as underlying the observed changes in abundance. The present study is simply an exploration of the abundance estimates of Pace et al. (2017), adding back known or expected fishery-related mortalities.

The bottom line is that without entanglement, the population would be in much better shape and would be more resilient to all other impacts mentioned above. The 2016 estimates of 562 and 588 in the bestcase scenarios of eliminating all fishery-related M\&SI and also accounting for lost reproduction, respectively, are 111 and 137 more whales than in the baseline model-increases of 24.6 and $30.4 \%$. If actual mortality is significantly more than double the detected rate, then eliminating fishery-related M\&SI entirely could have resulted in a population of well over 600 animals today. The addition of projected calves was also conservative, since any females that might have been included in the category of whales of unknown gender were not counted. Neither were any possible 'grand-calves,' although there were only 6 projected calves in 2000-2006 that would have reached the 10-yr age of first calving by the end of the study.

A disaster year like 2017 would have a significant impact on an endangered population under any conceivable scenario. Since only 5 calves were documented in 2017 (Pettis et al. 2017) and 17 dead whales were observed, the population declined by at least 12 animals (plus any undetected mortalities). The relative impact of a loss of 12 or more animals is more serious for a population of 451 whales $(2.66 \%)$ than it would have been for a stock of $562(2.14 \%)$ or $588(2.04 \%)$. A true population-dynamics model could be used to explore abundance and trends in much more detail-including future projections, more details of effects on population growth from not removing females, density-dependent effects of additional whales on fecundity and/or other parameters etc.; however, such a model was far beyond the scope of my study. In addition, it was not my real objective, which was, as simply as possible, to address questions about what the population would have done without fishery-related mortality.

The regulations that came into effect following the 1994 MMPA amendments specified that fisheryrelated M\&SI should be reduced below PBR within $6 \mathrm{mo}$ and to near 0 in $5 \mathrm{yr}$ (defined operationally as $10 \%$ of PBR, or 1 NARW removed every 10 or $11 \mathrm{yr}$ ). It has now been more than 2 decades, and we still are not even close. In fact, over the last several years, M\&SI numbers have been increasing (Table S1, Knowlton et al. 2012, 2016), with an appalling fishery-related M\&SI tally of 8 right whales in 2014 and a preliminary count of 7.75 for 2016 . The final tally for 2017 will not be known for some time. Some of the dead whales were likely killed by vessel collisions, other necropsy results are still being reviewed, and detailed case-by-case reviews of observed livewhale entanglements may result in some being 
determined to be serious injuries (https://www. fisheries.noaa.gov/national/marine-life-distress/20172018-north-atlantic-right-whale-unusual-mortalityevent). The 2017 M\&SI body counts will not be included in a SAR until the 2019 version, which will not be published until 2020. We cannot afford to wait that long to take action. Meyer-Gutbrod \& Greene (2018) modeled a range of future NARW population trajectories; under some foreseeable conditions, extinction within a century is likely. While this manuscript was being written and revised, it became clear that no calves were born in 2018. There may be little that we can do to affect NARW calving success, but the time is well past for substantial conservation actions to reduce human-caused mortality.

Acknowledgements. No study of NARWs would be possible without the long-term, collaborative efforts of the North Atlantic Right Whale Consortium (www.narwc.org) and the Consortium photo-identification catalog that was the basis of the study by Pace et al. (2017). I thank all of the many researchers who have contributed to the catalog, and the Consortium for access to the catalog data for reproductive histories. My work on managing the Consortium sightings database has been funded since 1986 by the National Marine Fisheries Service; however, this study was conducted on my own time using primarily open-source and public data sources. Comments from 3 anonymous referees greatly improved the clarity of this Note.

\section{LITERATURE CITED}

Cooke JG (2018) Eubalaena glacialis. IUCN Red List of Threatened Species 2018: e.T41712A50380891. https:// www.iucnredlist.org/species/41712/50380891

Hamilton PK, Knowlton AK, Marx MK (2009) Right whales tell their own stories: the photo-identification catalog. In: Kraus SD, Rolland RM (eds) The urban whale: North Atlantic right whales at the crossroads. Harvard University Press, Cambridge, MA, p 75-104

Hatch LT, Clark CW, Van Parijs SM, Frankel A, Ponirakis D (2012) Quantifying loss of acoustic communication space for right whales in and around a U.S. National Marine Sanctuary. Conserv Biol 26:983-994

Hayes SA, Josephson E, Maze-Foley K, Rosel PE and others (2018) US Atlantic and Gulf of Mexico Marine Mammal Stock Assessments - 2017. NOAA Tech Memo NMFS NE-

Editorial responsibility: Sascha Hooker, St. Andrews, UK
245. National Marine Fisheries Service, Woods Hole, MA * Knowlton AR, Hamilton PK, Marx MK, Pettis HM, Kraus SD (2012) Monitoring North Atlantic right whale Eubalaena glacialis entanglement rates: a 30 yr retrospective. Mar Ecol Prog Ser 466:293-302

Knowlton AR, Robbins J, Landry S, McKenna HA, Kraus SD, Werner TB (2016) Effects of fishing rope strength on the severity of large whale entanglements. Conserv Biol 30: 318-328

Kraus SD, Brown MW, Caswell H, Clark CW and others (2005) North Atlantic right whales in crisis. Science 309: 561-562

Kraus SD, Pace RM III, Frasier TR (2009) High investment, low return: the strange case of reproduction in Eubalaena glacialis. In: Kraus SD, Rolland RM (eds) The urban whale: North Atlantic right whales at the crossroads. Harvard University Press, Cambridge, MA, p 172-199

Meyer-Gutbrod EL, Greene CH (2018) Uncertain recovery of the North Atlantic right whale in a changing ocean. Glob Change Biol 24:455-464

Meyer-Gutbrod EL, Greene CH, Sullivan PJ, Pershing AJ (2015) Climate-associated changes in prey availability drive reproductive dynamics of the North Atlantic right whale population. Mar Ecol Prog Ser 535:243-258

NMFS (National Marine Fisheries Service) (2018) Marine mammal stock assessments. https://www.fisheries. noaa.gov/national/marine-mammal-protection/marinemammal-stock-assessments (accessed 14 August 2018)

Pace RM III, Corkeron PJ, Kraus SD (2017) State-space markrecapture estimates reveal a recent decline in abundance of North Atlantic right whales. Ecol Evol 7:8730-8741

* Pennisi E (2017) The North Atlantic right whale faces extinction. Science 358:703-704

Pettis HM, Pace RM III, Schick RS, Hamilton PK (2017) North Atlantic Right Whale Consortium 2017 Annual report card. https://www.narwc.org/uploads/1/1/6/6/116623219/ 2017_report_cardfinal.pdf

Rolland RM, Schick RS, Pettis HM, Knowlton AR, Hamilton PK, Clark JS, Kraus SD (2016) Health of North Atlantic right whales Eubalaena glacialis over three decades: from individual health to demographic and population health trends. Mar Ecol Prog Ser 542:265-282

* van der Hoop JM, Corkeron P, Kenney J, Landry S, Morin D, Smith J, Moore MJ (2016) Drag from fishing gear entangling North Atlantic right whales. Mar Mamm Sci 32: 619-642

* van der Hoop J, Corkeron P, Moore M (2017) Entanglement is a costly life history stage in large whales. Ecol Evol 7: 92-106

*Wade PR (1998) Calculating limits to the allowable humancaused mortality of cetaceans and pinnipeds. Mar Mamm Sci 14:1-37

Submitted: January 16, 2018; Accepted: September 25, 2018 Proofs received from author(s): October 27, 2018 